\title{
Review Article \\ Bioelectric State and Cell Cycle Control of Mammalian Neural Stem Cells
}

\author{
Julieta Aprea and Federico Calegari \\ DFG-Research Center and Cluster of Excellence for Regenerative Therapies, Medical Faculty, Dresden University of Technology, \\ Fetscherstrasse 105, 01307 Dresden, Germany \\ Correspondence should be addressed to Federico Calegari, federico.calegari@crt-dresden.de
}

Received 2 May 2012; Accepted 22 July 2012

Academic Editor: Stefan Liebau

Copyright ( $\odot 2012$ J. Aprea and F. Calegari. This is an open access article distributed under the Creative Commons Attribution License, which permits unrestricted use, distribution, and reproduction in any medium, provided the original work is properly cited.

\begin{abstract}
The concerted action of ion channels and pumps establishing a resting membrane potential has been most thoroughly studied in the context of excitable cells, most notably neurons, but emerging evidences indicate that they are also involved in controlling proliferation and differentiation of nonexcitable somatic stem cells. The importance of understanding stem cell contribution to tissue formation during embryonic development, adult homeostasis, and regeneration in disease has prompted many groups to study and manipulate the membrane potential of stem cells in a variety of systems. In this paper we aimed at summarizing the current knowledge on the role of ion channels and pumps in the context of mammalian corticogenesis with particular emphasis on their contribution to the switch of neural stem cells from proliferation to differentiation and generation of more committed progenitors and neurons, whose lineage during brain development has been recently elucidated.
\end{abstract}

\section{Introduction}

An extensive literature has described the features and properties of bioelectric gradients and signaling in a variety of tissues of many species during development, adulthood, and regeneration [1-5]. In particular for the developing nervous system, it has become clear that the concerted action of membrane channels and ion pumps establishing a resting membrane potential $\left(V_{\mathrm{mem}}\right)$ and other bioelectric parameters plays important roles in migration, survival, maturation, and functionality of newborn neurons [6-8]. Certainly less investigated is whether similar parameters may also play a role in controlling the switch of neural stem and progenitor cells (altogether referred to as NSC) from proliferative to neurogenic divisions but various evidences have accumulated in recent years making this possibility likely; in particular, when considering the multiple factors coupling bioelectric gradients and cell cycle progression $[1,7$, $9,10]$ as well as the effects of cell cycle length on proliferation versus differentiation of neural, and other somatic, stem cells $[11,12]$.
However, the limits of our knowledge in this area are particularly evident during mammalian brain development in which the establishment of new, sophisticated tools has only recently allowed the characterization of the physiological lineage of NSC. Specifically, during embryonic development of the mammalian cortex, polarized radial-glial cells, also referred to as apical progenitors (AP) forming the ventricular zone (VZ), progressively switch from divisions that generate additional AP to divisions that generate more committed, neurogenic progenitors leaving the VZ to form the subventricular zone (SVZ) at its pial, or basal, boundary; hence the name basal progenitors (BP) $[13,14]$. BP lose polarity, have limited self-renewal potential, and are soon consumed through symmetric neurogenic divisions to generate a pair of postmitotic neurons that migrate towards the pial surface to form the various neuronal layers of the mammalian cortex $[13,14]$ (Figure 1). Currently, most mammalian cortical neurons are thought to be derived from $\mathrm{BP}$, rather than $\mathrm{AP}$, and, interestingly, the appearance of this subpopulation of cells specifically in mammals has been proposed to be a critical step through which the massive enlargement in 


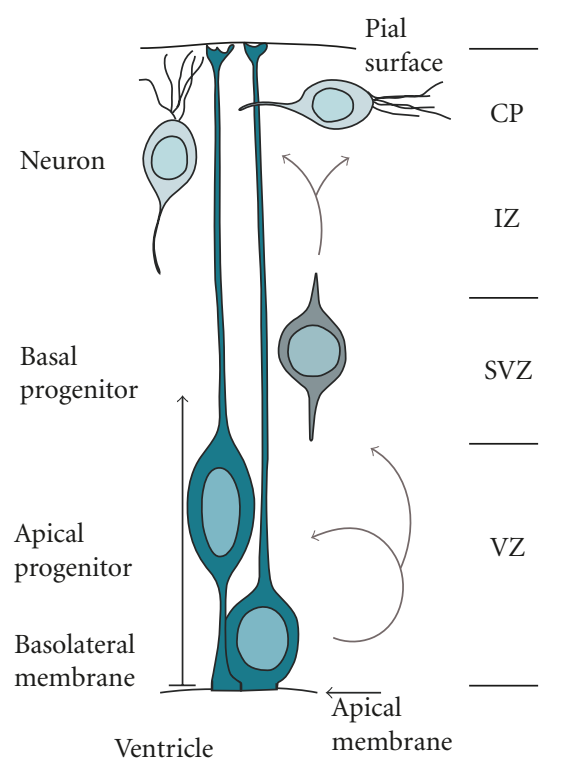

Figure 1: Scheme representing cell types in the developing mammalian cortex with (from top to bottom) neurons, basal (BP), and apical (AP) progenitors forming the cortical plate (CP), intermediate (IZ), subventricular (SVZ), and ventricular (VZ) zones, respectively. Lineages are depicted (arrows). Note the distinction between apical and basolateral plasma membrane of AP establishing the apicobasal polarity of the developing cortex.

cortical surface area has been achieved during evolution of our species [15-17].

Unfortunately, major technical limitations in investigating the role of bioelectric signals in neurogenic commitment during development have prompted most groups to use nonmammalian organisms, lacking BP, as model systems. Moreover, of the few reports in which mammalian NSC have been used, the vast majority were carried out in cultures of dissociated cells in which the loss of positional information and polarity makes it difficult to identify and compare characteristics of AP and BP. For these reasons, our knowledge about bioelectric signaling during mammalian brain development is very limited and its role in controlling the switch from proliferating AP to neurogenic BP can only be retrospectively inferred from previous studies in which these questions were, if any, only indirectly addressed.

Other authors have already summarized our current knowledge about a potential role of bioelectric signaling in stem cell function in various tissues or, within the nervous system, without considering progenitor lineages of the mammalian cortex [1-4, 7-9]. Thus, in this paper we attempted to make the retrospective links that may help address its role in the switch of mammalian NSC from proliferation to neurogenesis, which is fundamental towards understanding brain development and, perhaps, designing novel approaches of therapy of the mammalian central nervous system. Considering the extensive breadth of this area of research, we decided to focus our attention exclusively on the role of ion channels and pumps and their role in establishing a resting membrane potential in mammalian NSC of the developing embryo without discussing other bioelectric features, such as capacitance and input resistance, or additional roles of ion channels and metabotropic transporters involved in intracellular $\mathrm{Ca}^{2+}$ signaling, that were discussed elsewhere [1-8].

\section{Establishing a Resting Membrane Potential in NSC}

The fundamental mechanisms controlling the resting membrane potential of NSC are essentially identical to those of any other cell type being regulated by the permeability of ion channels and the activity of ion pumps and exchangers establishing ion gradients across membranes $[8,18-20]$. Members of the first group include "leak" as well as voltageand ligand-gated channels that allow the passive diffusion of ions through membranes after opening as a result of a change in voltage or binding to a specific ligand, respectively $[18,20]$. Examples of the second group include various types of ATPases and other enzymatic complexes exchanging ions through membranes against their gradients by consumption of energy, including the ubiquitous $\mathrm{Na}^{+} / \mathrm{K}^{+}, \mathrm{H}^{+}, \mathrm{Ca}^{2+}$ ATPases, and $\mathrm{Na}^{+} / \mathrm{K}^{+} / \mathrm{Cl}^{-}$cotransporters covering almost the whole spectrum of biologically relevant ions $[18,19]$. The roles of the three major classes of ion channels and pumps in embryonic mammalian neurogenesis will be discussed separately.

2.1. Voltage-Gated Ion Channels. The study of voltagegated ion channels has been particularly important for understanding the origin of action potentials, but recent evidences suggest that they may play important roles also in nonexcitable cells such as NSC. Several channels responsible for establishing a $V_{\text {mem }}$ in NSC during development [21] and adulthood [22] have been characterized, but many discrepancies and uncertainties remain with regard to the specific features of the bioelectric state and signaling in different subpopulations of NSC. In particular, of the main types of voltage-gated $\mathrm{K}^{+}$currents both outward, delayed rectifier [21,23-25] and inward rectifier currents in response to hyperpolarizing pulses [21] were detected. On the other hand, fast, A-type, transient outward $\mathrm{K}^{+}$currents were detected in NSC cultures [21,23-25] but not in the VZ of organotypic slices [26].

Since the resting membrane potential of most animal cells is slightly higher than the reversal potential of $\mathrm{K}^{+}$, the overall effect of blocking $\mathrm{K}^{+}$channels is to promote depolarization; this most typically correlates with increased cell proliferation. In fact, voltage-gated $\mathrm{K}^{+}$currents are involved in the regulation of the ce 11 cycle, in particular G1, in many cell types $[1,7,9,10,27]$, including NSC $[8$, $22]$, and treating NSC with certain $\mathrm{K}^{+}$channels antagonists promoted their proliferation in a number of assays [23, 2830]. For example, blockage of voltage-gated delayed rectifier $\mathrm{K}^{+}$channels in cells isolated from rat midbrain increased the proportion of dividing precursors from ca. 10 to $30 \%$ [23]. In 12-week human fetal NSC, inhibition of delayed-rectifier $\mathrm{K}^{+}$channels either did not affect proliferation or increased it, 
depending on the blocker used, while inhibition of A-type $\mathrm{K}^{+}$ channels impaired cell viability [29]. This proliferation effect of certain blockers of $\mathrm{K}^{+}$channels has also been confirmed in adult neurogenic or embryonic gliogenic progenitors in which increased or decreased proliferation has been observed depending on which particular subtype of $\mathrm{K}^{+}$channels has been blocked $[28,30]$. Along these lines, a block in $\mathrm{K}^{+}$channels in oligodendrocyte progenitors correlated with inhibited proliferation and an increase in the levels of the G1specific cyclin-dependent kinase inhibitors p21 and p27 [31].

Reconciling these partly contrasting results is difficult not only because the pharmacological approaches and origin of NSC varied among studies but also because effects on membrane potential as a result of a block of one given type of $\mathrm{K}^{+}$channel were rarely measured to corroborate effects on de- versus hyperpolarization.

The $\mathrm{K}^{+}$currents found in NSC are also present in immature neurons in which inward $\mathrm{Na}^{+}$currents soon appear that increase their amplitude during neuronal maturation until reaching values characteristic of mature neurons $[26,32]$. In contrast to $\mathrm{K}^{+}$, the presence of voltage-gated $\mathrm{Na}^{+}$channels in NSC is controversial. Several studies have detected low $\mathrm{Na}^{+}$currents in NSC preparations, but these were present only in a relatively small subpopulation of cells of which most have been classified as early born neurons $[21,33]$, a conclusion that was also corroborated by direct measurement of NSC in the VZ of mouse cortical slices [34]. Nevertheless, it cannot be excluded that $\mathrm{Na}^{+}$currents may appear in more committed neurogenic progenitors, such as $\mathrm{BP}$, since these cells were reported to initiate the expression of genes characteristically identifying postmitotic neurons $[35,36]$. This possibility is consistent with the detection of $\mathrm{Na}^{+}$current in only a subpopulation of cortical progenitors [33] and is not invalidated by the absence of $\mathrm{Na}^{+}$currents in the VZ [34] since this latter study was limited to cells with radial morphology, that is, AP.

Direct evidence for the appearance of depolarizing $\mathrm{Na}^{+}$ currents in the transition from AP to $\mathrm{BP}$ can be retrospectively inferred from a study by Bahrey and Moody in which organotypic slice cultures from the embryonic day (E) 14 mouse brain were used to measure bioelectrical parameters of different progenitor subtypes [26]. Upon labeling with vital dyes, the authors could identify radial versus nonradial cells within the $\mathrm{VZ}$ observing a bias for the presence of $\mathrm{Na}^{+}$currents in the latter population [26]. Interestingly, the proportion of cells in the VZ displaying $\mathrm{Na}^{+}$currents increased during development from 0,30 , and then $50 \%$ at E9, E14 and E16, respectively [26]. Not only these values fit remarkably well with the proportion of BP detected in the VZ [37], but one year after the study by Bahrey and Moody three independent reports could also demonstrate that the vast majority of nonradial cell in the $\mathrm{VZ}$ are, indeed, $\mathrm{BP}$ [38-40]. Thus, it can now be retrospectively concluded that the work by Bahrey and Moody provided the first strong evidence for a difference in AP versus BP currents at a time when, remarkably, cellular and molecular features of BP were not even characterized.

Similar to $\mathrm{K}^{+}$, the presence of voltage-gated $\mathrm{Ca}^{2+}$ currents in NSC is consistently reported by various studies. Inward currents were detected in cells within the VZ in brain slices and dissociated cultures $[26,41,42]$, and since similar currents were elicited also in preparations from E10 rat spinal cord [21], that are known to lack BP, it is likely that voltage-gated $\mathrm{Ca}^{2+}$ channels are a feature of all NSC. In cells isolated from human embryonic central nervous sytem [43] and P0 mouse cortex [44] small $\mathrm{Ca}^{2+}$ currents were only detected upon differentiation conditions in cells with neuronal morphology. Treating NSC with blockers of Ltype voltage-gated $\mathrm{Ca}^{2+}$ channels has been found to reduce the number of neurons in differentiation conditions while, conversely, activating the channels triggered the opposite effect [44]. Yet, since the same experiments failed to detect $\mathrm{Ca}^{2+}$ currents in undifferentiated NSC [44], it may be concluded that the different number of neurons detected in this study may be attributed to effects on neuronal survival or an altered timing in the expression of neuronal markers in postmitotic cells rather than to a change in the fate of NSC proper.

The expression pattern during development of the fourth type of ion channels, $\mathrm{Cl}^{-}$, has also been described [45], but functional experiments on their role in NSC differentiation are missing.

Altogether, several reports point to a role of voltage-gated ion channels in NSC proliferation with $\mathrm{K}^{+}$channels being more consistently implicated in this process. Most studies in this area were performed using dissociated cells, or in slice cultures but without considering different progenitor subtypes, thus making it difficult to infer differences between $\mathrm{AP}$ and $\mathrm{BP}$; the latter probably being characterized by the presence of $\mathrm{Na}^{+}$currents [26]. It has been suggested that depolarization has a positive effect on proliferation $[1,7,9]$, and many of the studies discussed above extend this view to NSC via manipulations that alter the activity of voltage-gated ion channels (Figure 2). Yet, the molecular mechanisms underlying this correlation are unknown.

2.2. Ligand-Gated Ion Channels. The study of ligandgated ion channels is most typically associated with the understanding of neurotransmitter-dependent excitability of neurons and neuroendocrine cells, but evidences collected over the years have shown that at least two ligands, $\gamma$ aminobutyric acid (GABA) and glutamate, play important roles in NSC activity not only in the adult [46] but also in the developing brain even before functional synapses are formed [41, 47, 48].

Among the most extensively studied, the $\mathrm{GABA}_{\mathrm{A}}$ receptor is a ligand-gated $\mathrm{Cl}^{-}$channel and because of the particular pattern of $\mathrm{Cl}^{-}$transporters expressed in NSC of the embryonic brain $[49,50]$, these cells present a low $\mathrm{Cl}^{-}$reversal potential implying that during development GABA depolarizes NSC and immature neurons instead of hyperpolarizing them as it does in the mature brain [48]. Functional $\mathrm{GABA}_{\mathrm{A}}$ receptors and GABA are expressed in mammalian NSC during brain development [41, 51] acting through paracrine/autocrine signaling $[47,52,53]$, and NSC in the VZ start to respond to GABA by depolarizing $V_{\text {mem }}$ at E15 but not before [41]. The cellular origin of nonsynaptic 


\begin{tabular}{|c|c|c|c|c|}
\hline \begin{tabular}{|c|} 
Parameter \\
manipulated
\end{tabular} & Type of manipulation & Proliferation & $\begin{array}{l}\text { Developmental } \\
\text { stage/region }\end{array}$ & Reference \\
\hline \multirow{5}{*}{$I_{k}$} & Kv1.3 block, Psora-4 & $\uparrow$ & rE14.5 mid, dissociated cells & {$[23]$} \\
\hline & Kv3.1 block, TEA & $\uparrow$ & rE14.5 mid, dissociated cells & {$[23]$} \\
\hline & Inhibition, QND (low dose) & $=$ & hW12, dissociated cells & [29] \\
\hline & Inhibition, DTX & $\uparrow$ & hW12, dissociated cells & {$[29]$} \\
\hline & Inhibition, FSK & $\downarrow$ & rE20 Cx,O-2A prog. & {$[31]$} \\
\hline$I_{A}$ & Inhibition, 4- $\mathrm{AP} / \mathrm{PTX} / \mathrm{NH}_{4} \mathrm{Cl}$ & $\downarrow *$ & hW12, dissociated cells & [29] \\
\hline \multirow{2}{*}[\mathrm{K}^{+}]{$_{e}$} & $20 \mathrm{mM} \mathrm{KCl}$ (depolarization) & $\downarrow$ & rE17 Cx, slices VZ + SVZ & {$[41]$} \\
\hline & $5 \mathrm{mM} \mathrm{KCl}$ (depolarization) & $\uparrow$ & rE15 LGE, dissociated cells & {$[64]$} \\
\hline \multirow{9}{*}{ 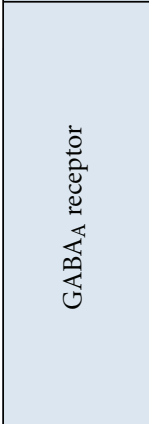 } & Agonist, GABA & $=$ & rE14Cx, slices VZ+SVZ & {$[41]$} \\
\hline & Agonist, GABA & $\downarrow$ & rE16 and $19 \mathrm{Cx}$, slices VZ + SVZ & {$[41]$} \\
\hline & Agonist, GABA/muscitol & $\uparrow$ & mE13 and $14 \mathrm{Cx}$, slices, $\mathrm{VZ}$ & {$[56]$} \\
\hline & Agonist, GABA/muscitol & $\downarrow$ & $\mathrm{mE} 13$ and $14 \mathrm{Cx}$, slices, SVZ & {$[56]$} \\
\hline & Agonist, GABA/muscitol & $\downarrow * *$ & rE16 Cx, dissociated cells & {$[54]$} \\
\hline & Antagonist, BMI & $=$ & rE16 Cx, slices VZ + SVZ & {$[41]$} \\
\hline & Antagonist, BMI & $\uparrow$ & rE19 Cx, slices VZ + SVZ & {$[41]$} \\
\hline & Antagonist, BMI & $=$ & $\mathrm{mE} 13$ and $14 \mathrm{Cx}$, slices, $\mathrm{VZ}$ & {$[56]$} \\
\hline & Antagonist, BMI & $\downarrow$ & $\mathrm{mE} 13$ and $14 \mathrm{Cx}$, slices, SVZ & {$[56]$} \\
\hline \multirow{2}{*}{ GlutamateR } & Agonist, glutamate & $\downarrow$ & rE16 and $19 \mathrm{Cx}$, slices VZ + SVZ & {$[41]$} \\
\hline & Agonist, glutamate & $\uparrow$ & hW10-16 Cx, dissociated cells & {$[65]$} \\
\hline \multirow{11}{*}{ 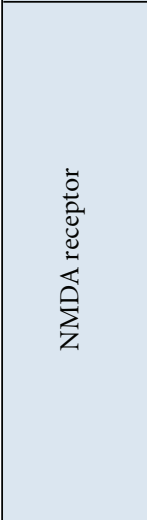 } & Agonist, glutamate + MK-801 & $=$ & hW10-16 Cx, dissociated cells & {$[65]$} \\
\hline & Agonist, NMDA & $=$ & rE16 and $19 \mathrm{Cx}$, slices $\mathrm{VZ}+\mathrm{SVZ}$ & {$[41]$} \\
\hline & Agonist, NMDA & $\uparrow$ & rE15 LGE, dissociated cells & {$[64]$} \\
\hline & Agonist, NMDA & $\uparrow$ & rE16 Hp, dissociated cells & {$[42]$} \\
\hline & Antagonist, D-APV & $\uparrow$ & rE17 Cx, slices, VZ and SVZ/cells & {$[62]$} \\
\hline & Antagonist, MK-801/CGS-19755 & $\downarrow(1)$ & rE15-18, in utero & {$[64]$} \\
\hline & Antagonist, MK-801 & $=(2)$ & rE15-18, in utero & {$[64]$} \\
\hline & Antagonist, MK-801 & $\downarrow$ & rE15-16 LGE, in utero, VZ & {$[64]$} \\
\hline & Antagonist, MK-801 & $=$ & rE15-16 LGE, in utero, SVZ & {$[64]$} \\
\hline & Antagonist, MK-801/CGS-19755 & $\downarrow$ & rE15 LGE, dissociated cells & {$[64]$} \\
\hline & Antagonist, MK-801 & $=$ & rE16 Hp, dissociated cells & {$[42]$} \\
\hline \multirow{10}{*}{ 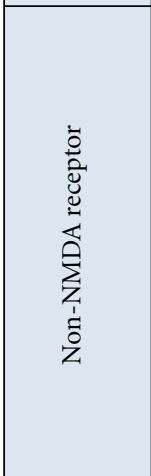 } & Agonist, kainate & $=$ & rE14 Cx, slices VZ + SVZ & {$[41]$} \\
\hline & Agonist, kainate & $\downarrow$ & rE16 and $19 \mathrm{Cx}$, slices $\mathrm{VZ}+\mathrm{SVZ}$ & {$[41]$} \\
\hline & Agonist, glutamate/kainate & $\uparrow$ & mE13 and $14 \mathrm{Cx}$, slices, VZ & {$[56]$} \\
\hline & Agonist, glutamate/kainate & $\downarrow$ & mE13 and $14 \mathrm{Cx}$, slices, SVZ & {$[56]$} \\
\hline & Antagonist, CNQX & $=$ & rE16 Cx, slices VZ + SVZ & {$[41]$} \\
\hline & Antagonist, CNQX & $\uparrow$ & rE19 Cx, slices VZ + SVZ & {$[41]$} \\
\hline & Antagonist, CNQX & $\downarrow$ & $\mathrm{mE} 13$ and $14 \mathrm{Cx}$, slices, $\mathrm{VZ}$ & {$[56]$} \\
\hline & Antagonist, CNQX & $\downarrow$ & mE13 and $14 \mathrm{Cx}$, slices, SVZ & {$[56]$} \\
\hline & Antagonist, NQBX & $=(1)$ & rE15-18, in utero & {$[64]$} \\
\hline & Antagonist, NQBX & $=$ & rE15 LGE, dissociated cells & {$[64]$} \\
\hline
\end{tabular}

FIGURE 2: Effects upon manipulation of ion channels or extracellular ionic composition on the proliferation of NSC. Green and red arrows indicate increased or decreased proliferation, respectively, as deduced from incorporation of thymidine analogues or number of neurons in the adult striatum (1) or motor cortex (2). Agonists and antagonists used (Psora-4 = 5-(4-phenylbutoxy)psoralen; TEA = tetraethylammonium chloride; $\mathrm{QND}=$ quinidine; $\mathrm{DTX}=\alpha$-dendrotoxin; FSK = forskolin; 4-AP = 4-aminopyridine; PTX = phrixotoxin; BMI = biculline methionine; $\mathrm{D}-\mathrm{APV}=\mathrm{D}(-)$-2-amino-5-phosphonopentanoicacid; $\mathrm{CNQX}=$ 6-cyano-7-dinitroquinoxaline-2,3-dione; NQBX = 1,2,3,4-tetrahydro-6-nitro-2,3-dioxo-benzol(f)-quinoxaline-7-sulfonamide) as well as source of NSC form different species $(\mathrm{r}=\mathrm{rat}$; $\mathrm{h}=$ human; $\mathrm{m}=$ mouse), developmental stage $(\mathrm{E}=$ embryonic day; $\mathrm{W}=$ embryonic week), or region $(\mathrm{mid}=\mathrm{midbrain}$; $\mathrm{Cx}=\mathrm{cortex} ; \mathrm{LGE}$ = lateral ganglionic eminence; $\mathrm{Hp}=$ hippocampus; $\mathrm{VZ}=$ ventricular zone; $\mathrm{SVZ}=$ subventricular zone) are indicated. ${ }^{*}$ reduced viability; ** only in the presence of bFGF; O-2A = oligodendrocyte progenitors. 
GABA release is still controversial, but there is evidence for the presence of a synthetic machinery in NSC [51].

Several studies have pointed to an effect of GABA on NSC proliferation. LoTurco et al. found that GABA inhibits DNA synthesis in embryonic rat cortical explants and since GABA caused a reversible increase in $\left[\mathrm{Ca}^{2+}\right]_{i}$, and depolarization by $\mathrm{K}^{+}$had similar effects to GABA, the authors hypothesized that the effect on proliferation is mediated through activation of voltage-gated $\mathrm{Ca}^{2+}$ channels [41]. Consistently, GABA administration on dissociated cells was found to inhibit proliferation while promoting differentiation $[54,55]$. On the other hand, Haydar et al. subsequently observed that GABA increased proliferation with a shortening of the cell cycle and decreased differentiation in the VZ while, interestingly, the opposite effect was found in the SVZ, where BP reside [56]. Clearly, differences between AP and BP were lost when NSC were pulled together [41] or studied using dissociated cultures $[54,55]$. Other reports have also pointed to a positive effect of GABA on proliferation [57], and a vast literature has described its many effects on survival, migration, maturation, and synaptogenesis of newborn neurons $[48,52,53]$.

Glutamate is the principal excitatory neurotransmitter in the adult cerebral cortex whose signals, as for GABA, are mediated by ionotropic and metabotropic receptors. The former group is further subdivided into three types based on their pharmacological and electrophysiological properties and named after their specific agonists: NMDA, AMPA, and KA receptors [58]. Considering the similar effect of GABA and glutamate on depolarization, it is not surprising that both neurotransmitters elicited similar effects on NSC.

The presence of NMDA receptors in NSC has been reported in several systems including NSC lines, primary cultures, and organotypic slice preparations displaying low expression levels of this receptor and small NMDA-mediated currents [59-62]. The fact that the NMDA-elicited currents observed in the $\mathrm{VZ}$ are all but a small fraction of those in the cortical plate, where neurons reside, [62] may explain why these currents were not detected by previous studies [41].

One early work reported increased proliferation upon block of NMDA receptors in NSC of the VZ and SVZ in slice cultures [62], but later studies consistently reached the opposite conclusion by showing that agonists of NMDA receptors increase proliferation while, conversely, antagonists trigger the opposite effect in vitro and in vivo [42, 63-65].

AMPA and KA receptors are expressed during development as early as E10 [60, 66]. In rat cortical slices, an increasing proportion of cells in the $\mathrm{VZ}$ depolarized upon AMPA or KA exposure as a function of developmental time from 0 to $100 \%$ between E14 and E16 [41]. Exposure to KA in rat cortical slices decreased NSC proliferation [41], while exposure to AMPA or KA agonists in mouse cortical slices shortened the cell cycle in the VZ but had the opposite effect on the SVZ while inhibiting neurogenesis [56].

Other ionotropic receptors for glycine, acetylcholine, and serotonin have also been implicated in neuronal development but primarily in the maturation, migration, synaptogenesis, and circuit formation of postmitotic neurons rather than in the regulation of NSC proliferation versus differentiation proper $[52,53]$.

Most of the limitations discussed in the context of voltage-dependent ion channels with regard to their involvement in AP to BP transition during mammalian cortical development hold true for ligand-dependent ion channels, and equally valid is the overall positive correlation between manipulations that depolarize NSC and increased proliferation (Figure 2).

2.3. Ion Pumps. The third big family of proteins essential for establishing an electric potential across membranes comprises enzymatic macrocomplexes converting energy, most typically chemical in the form of ATP or electrochemical gradients, to pump ions against their concentration gradient $[18,19]$. An additional, and equally important, role of certain pumps is to regulate the concentration of ions in intracellular compartments as, for example, in the case of the ubiquitous $\mathrm{H}^{+}$ATPase responsible for the acidification of endosomes and other organelles $[67,68]$.

Despite their importance in a number of fundamental biological processes, few studies have addressed the effects of manipulating the activity of ion pumps in neural development; even fewer were focused on mammalian corticogenesis. For example, the $\mathrm{Na}^{+} / \mathrm{K}^{+}$and $\mathrm{Ca}^{2+}$ ATPases have been shown to mediate dendritic outgrowth of mammalian cortical neurons [69] and midline signaling in zebrafish embryos [70]. Loss of function of the $\mathrm{H}^{+}$ATPase in Xenopus has been shown to inhibit development and regeneration $[71,72]$, while gain of function had the opposite effect [71].

Due to their multiple roles $[67,68]$, it is currently difficult to determine to which extent the effects induced by manipulations of ATPases are primarily due to a change in membrane potential as compared to other functions including endocytosis, trafficking, and signaling. Nevertheless, several observations suggest that the latter functions may be the most relevant ones during development. In particular, manipulations of the $\mathrm{Na}^{+} / \mathrm{K}^{+}$ATPase during dendritogenesis of rat cortical neurons were not accompanied by a change in membrane potential but rather by a change in $\mathrm{Ca}^{2+}$ /calmodulin-dependent protein kinase signaling and cAMP-responsive element gene expression [69]. Moreover, the inhibition of $\mathrm{Ca}^{2+}$ ATPases that was shown to induce developmental defects in zebrafish was achieved by manipulating pumps specifically of the endoplasmic reticulum leading to increased intracellular $\mathrm{Ca}^{2+}$ and, thus altering the complex $\mathrm{Ca}^{2+}$-dependent signaling events occurring during development more than changing $V_{\text {mem }}$ proper [70]. Finally, with regard to the role of the $\mathrm{H}^{+}$ATPase various laboratories have independently shown that its inhibition affects the transduction of important signaling molecules, such as Notch [73, 74] and Wnt [75], that are known to control proliferation, tissue patterning, and development throughout the animal kingdom [76-79].

While essentially all experiments on the role of the $\mathrm{H}^{+}$ ATPase in stem cell differentiation were performed in nonmammalian species, recent evidences from our laboratory could extend the role of this proton pump in Notch signaling 
during mammalian cortical development [80]. In these experiments, a dominant-negative subunit of the $\mathrm{H}^{+}$ATPase was overexpressed during mouse embryonic development in NSC triggering their premature differentiation through a reduction of endogenous Notch signaling [80]. These and other experiments $[73,74,80]$ support the notion that intracellular cleavage of activated Notch requires trafficking through acidic endosomes [81-83], but the intrinsic difficulties in distinguishing between cell autonomous versus extrinsic effects, and reports showing that Notch signaling may not require endocytosis [84-86], have led to a long debate in the field. Nevertheless, the fact that ATPases can have multiple effects at the level of (i) the cell biophysical state, (ii) signaling of differentiation molecules, and (iii) cell cycle length, places these enzymatic complexes in an ideal position to control the differentiation of NSC during mammalian corticogenesis.

Cation-chloride cotransporters are a family of membrane proteins that use the $\mathrm{Na}^{+} / \mathrm{K}^{+}$transmembrane electrochemical gradient to transport $\mathrm{Cl}^{-}$against its gradient. This family is composed by seven members, most of which are expressed in neurons, with only one $\mathrm{K}^{+}$(KCC4) and one $\mathrm{Na}^{+}$(NKCC1) coupled cotransporters being detected in the proliferative zones of the developing cortex and being responsible for pumping $\mathrm{Cl}^{-}$outside or inside the cell, respectively $[49,50$, 87]. KCC4 expression is specific for the VZ and SVZ and its levels seem to increase during development from E12 to E14 and disappear perinatally [50]. NKCC1 expression in NSC similarly increases during development, but it then switches from NSC to neurons before birth [50].

The high expression of NKCC1 in the embryonic VZ [50] provides an explanation for the high $\left[\mathrm{Cl}^{-}\right]_{\mathrm{i}}$ underlying $\mathrm{GABA}_{\mathrm{A}}$ depolarization response in AP $[50,88]$. In addition to NSC, NKCC1 is also highly expressed in immature cortical neurons from E18 to the first postnatal week $[49,50]$ while KCC2 shows a marked increase only after the first postnatal week $[45,49,50]$. These changes in the composition of $\mathrm{Cl}^{-}$ transporters during the first weeks of life are probably the cause for the reduced $\left[\mathrm{Cl}^{-}\right]_{\mathrm{i}}$ responsible for the excitatory versus inhibitory effects of GABA [88-91].

\section{Membrane Potential and Proliferation versus Differentiation of NSC}

The primary role of the concerted action of ion channels and pumps is to regulate the $V_{\text {mem }}$ of cells and, thus, it is reasonable to assume that their effect on proliferation of NSC should be interpreted in the context of this function.

Various groups have measured the membrane potential of mammalian NSC during embryonic development by different approaches resulting in $V_{\text {mem }}$ values that ranged from a maximum of $-40 \mathrm{mV}$ to a minimum of $-70 \mathrm{mV}$ [21, $25,26,50,88,92-94]$. Because a higher proliferative activity is known to correlate with a less negative, or depolarized, $V_{\text {mem }}[1,7,9]$ and NSC, in particular BP, lengthen their cell cycle as development proceed $[12,95]$, it would be expected that the different $V_{\text {mem }}$ measured by the different authors should reflect the use of NSC at different developmental stages. Reinforcing this expectation, more negative, or hyperpolarized, $V_{\text {mem }}$ during development may also be deduced from the fact that (i) adult NSC tend to be more hyperpolarized than embryonic NSCs [22], (ii) the activity of the $\mathrm{K}^{+} / \mathrm{Na}^{+} / 2 \mathrm{Cl}^{-}$transporter decreases during development [88], and (iii) developmentally regulated growth factors and signaling molecules influencing the cell cycle also influence the activity of ion channels $[32,96]$. Yet, while comparing the measurements performed at different developmental stages, or from different regions of the central nervous system that contain, or lack, BP, [21, 25, 26, 50, 88, 92-94] we were unable to detect any specific trend.

Certainly, the lack of evidence for a change in $V_{\text {mem }}$ during development, and in particular between AP and BP, should not be considered as an evidence for its lack since this comparison has never been directly pursued. Many of the reports discussed above are consistent with the view that an artificial depolarization of NSC may increase their proliferative potential and delay neurogenesis, but some are not and reconciling them is particularly difficult if one considers the diverse approaches and experimental condition used among studies including NSC of different origins and culture conditions, diverse pharmacological approaches to manipulate the activity of various ion channels or pumps without necessarily measuring an effect on $V_{\text {mem }}$ or, even less so, cell cycle length. Moreover, in nearly all studies discussed, it is difficult to assess whether hyperpolarization is a cell-intrinsic feature of a given subpopulation of differentiating NSC, such as BP that increase in number during development, or, alternatively, an overall characteristic of tissues at different embryonic stages, as would be expected from the fact that ion concentrations in the cerebrospinal fluid fluctuate during mammalian development [97]. In fact, discriminating between these possibilities would require the measurement and manipulation of $V_{\text {mem }}$ concomitantly in two coexisting subpopulations of cells, such as multipotent $\mathrm{AP}$ and more committed $\mathrm{BP}$, at one given developmental time. Clearly, the ideal conditions to performing such experiments are those in which other bioelectric features of NSC, including capacitance, conductivity, and electric coupling mediated by junctions are preserved within an intact tissue.

The technical limitations intrinsic in these experiments are daunting, but recent developments provide the key towards addressing the role of $V_{\text {mem }}$ in mammalian neurogenesis.

\section{Conclusions}

For many years the lineage of NSC during mammalian corticogenesis has been indirectly inferred from fixed tissues or retrospectively deduced upon S-phase labeling in vivo. Only recently has the establishment of time-lapse videomicroscopy and transgenesis evolved to the point that direct visualization of $\mathrm{AP}$ and $\mathrm{BP}$ divisions in organotypic slice cultures became possible [38-40]. Moreover, the identification of molecular markers for BP [37], the generation of 
transgenic reporter mice allowing their visualization in alive tissues $[98,99]$, and new methods to genetically manipulate individual cells in brain cortical slices [100] while also monitoring G1/S/G2 progression [101] currently allow us to directly investigate the role of ion channels, pumps, and their effects on membrane potential during mammalian corticogenesis at the single-cell level. Overcoming the use of dissociated cells cultures and uncertainties with regard to the identity of different progenitors subtypes, these powerful new tools may allow us to reveal a new role of bioelectric signaling in NSC differentiation and likely reconcile the different reports that were discussed in this paper.

Similarly, great emphasis on the role of apicobasal polarity in $\mathrm{AP} / \mathrm{BP}$ transition and neurogenesis has recently come to light in particular in the context of asymmetric cleavage plane orientation [102], subcellular localization of cell cycle regulators [103], and evolution of the mammalian brain [104]. This in turn triggers the question as to whether or not the subcellular localization of certain channels or pumps, rather than their absolute expression levels, might be important for cell fate change. Unfortunately, however, identification of ion pumps and channels in tissues has been historically established by electrophysiology or, alternatively, by in situ hybridization, neither of which provides any information about protein localization. When immunohistochemical characterization was undertaken $[23,25,44,54$, $55,64,65]$, this was performed either on dissociated cells where apicobasal polarity is lost or in intact tissue but exclusively for the $\mathrm{Na}-\mathrm{K}-\mathrm{Cl}$ cotransporter that showed no preferential localization in the apicobasal axis [50].

Apparently, the two big fields comprising (i) cell biologists studying the cell cycle, lineage, and polarity of NSC and (ii) physiologists studying their channels, pumps, and membrane potential have seldom met. We hope that our paper may underline the importance of this interdisciplinary field.

\section{Acknowledgments}

J. Aprea and F. Calegari are supported by the DFG-funded Center for Regenerative Therapies, the Medical Faculty of the Dresden University of Technology, the Max Planck Institute of Molecular Cell Biology and Genetics, and the DFG-Collaborative Research Center SFB655 (subproject A20).

\section{References}

[1] M. Levin, "Large-scale biophysics: ion flows and regeneration," Trends in Cell Biology, vol. 17, no. 6, pp. 261-270, 2007.

[2] K. R. Robinson and M. A. Messerli, "Left/right, up/down: the role of endogenous electrical fields as directional signals in development, repair and invasion," BioEssays, vol. 25, no. 8, pp. 759-766, 2003.

[3] M. Zhao, "Electrical fields in wound healing — an overriding signal that directs cell migration," Seminars in Cell and Developmental Biology, vol. 20, no. 6, pp. 674-682, 2009.

[4] C. D. McCaig, A. M. Rajnicek, B. Song, and M. Zhao, "Controlling cell behavior electrically: current views and future potential," Physiological Reviews, vol. 85, no. 3, pp. 943-978, 2005.

[5] R. H. W. Funk and T. K. Monsees, "Effects of electromagnetic fields on cells: physiological and therapeutical approaches and molecular mechanisms of interaction. A review," Cells Tissues Organs, vol. 182, no. 2, pp. 59-78, 2006.

[6] R. B. Borgens, "Voltage gradients and ionic currents in injured and regenerating axons," Advances in neurology, vol. 47, pp. 51-66, 1988.

[7] C. D. McCaig, B. Song, and A. M. Rajnicek, "Electrical dimensions in cell science," Journal of Cell Science, vol. 122, no. 23, pp. 4267-4276, 2009.

[8] N. C. Spitzer, "Electrical activity in early neuronal development," Nature, vol. 444, no. 7120, pp. 707-712, 2006.

[9] D. J. Blackiston, K. A. McLaughlin, and M. Levin, "Bioelectric controls of cell proliferation: ion channels, membrane voltage and the cell cycle," Cell Cycle, vol. 8, no. 21, pp. 35193528, 2009.

[10] L. A. Pardo, "Voltage-gated potassium channels in cell proliferation,” Physiology, vol. 19, no. 5, pp. 285-292, 2004.

[11] C. Lange and F. Calegari, "Cdks and cyclins link G(1) length and differentiation of embryonic, neural and hematopoietic stem cells," Cell Cycle, vol. 9, no. 10, pp. 1893-1900, 2010.

[12] P. Salomoni and F. Calegari, "Cell cycle control of mammalian neural stem cells: putting a speed limit on G1," Trends in Cell Biology, vol. 20, no. 5, pp. 233-243, 2010.

[13] M. Götz and W. B. Huttner, "The cell biology of neurogenesis," Nature Reviews Molecular Cell Biology, vol. 6, no. 10, pp. 777-788, 2005.

[14] A. Kriegstein and A. Alvarez-Buylla, "The glial nature of embryonic and adult neural stem cells," Annual Review of Neuroscience, vol. 32, pp. 149-184, 2009.

[15] A. Pontious, T. Kowalczyk, C. Englund, and R. F. Hevner, "Role of intermediate progenitor cells in cerebral cortex development," Developmental Neuroscience, vol. 30, no. 1-3, pp. 24-32, 2007.

[16] A. Kriegstein, S. Noctor, and V. Martínez-Cerdeño, "Patterns of neural stem and progenitor cell division may underlie evolutionary cortical expansion," Nature Reviews Neuroscience, vol. 7, no. 11, pp. 883-890, 2006.

[17] J. H. Lui, D. V. Hansen, and A. R. Kriegstein, "Development and evolution of the human neocortex," Cell, vol. 146, no. 1, pp. 18-36, 2011.

[18] E. Gouaux and R. MacKinnon, "Principles of selective ion transport in channels and pumps," Science, vol. 310, no. 5753, pp. 1461-1465, 2005.

[19] R. Blostein, "Ion pumps," Current Opinion in Cell Biology, vol. 1, no. 4, pp. 746-752, 1989.

[20] N. Unwin, "Neurotransmitter action: opening of ligandgated ion channels," Cell, vol. 72, no. 1001, supplement, pp. 31-41, 1993.

[21] J. Cai, A. Cheng, Y. Luo et al., "Membrane properties of rat embryonic multipotent neural stem cells," Journal of Neurochemistry, vol. 88, no. 1, pp. 212-226, 2004.

[22] T. Yasuda and D. J. Adams, "Physiological roles of ion channels in adult neural stem cells and their progeny," Journal of Neurochemistry, vol. 114, no. 4, pp. 946-959, 2010.

[23] S. Liebau, C. Pröpper, T. Böckers et al., "Selective blockage of Kv1.3 and Kv3.1 channels increases neural progenitor cell proliferation," Journal of Neurochemistry, vol. 99, no. 2, pp. 426-437, 2006.

[24] T. Li, L. Jiang, H. Chen, and X. Zhang, "Characterization of excitability and voltage-gated ion channels of neural 
progenitor cells in rat hippocampus," Journal of Molecular Neuroscience, vol. 35, no. 3, pp. 289-295, 2008.

[25] D. O. Smith, J. L. Rosenheimer, and R. E. Kalil, "Delayed rectifier and A-type potassium channels associated with $\mathrm{Kv}$ 2.1 and $\mathrm{Kv} 4.3$ expression in embryonic rat neural progenitor cells," PLoS One, vol. 3, no. 2, Article ID e1604, 2008.

[26] H. L. P. Bahrey and W. J. Moody, "Voltage-gated currents, dye and electrical coupling in the embryonic mouse neocortex," Cerebral Cortex, vol. 13, no. 3, pp. 239-251, 2003.

[27] W. F. Wonderlin and J. S. Strobl, "Potassium channels, proliferation and G1 progression," Journal of Membrane Biology, vol. 154, no. 2, pp. 91-107, 1996.

[28] S. N. MacFarlane and H. Sontheimer, "Changes in ion channel expression accompany cell cycle progression of spinal cord astrocytes," Glia, vol. 30, pp. 39-48, 2000.

[29] G. Schaarschmidt, F. Wegner, S. C. Schwarz, H. Schmidt, and J. Schwarz, "Characterization of voltage-gated potassium channels in human neural progenitor cells," PLoS One, vol. 4, no. 7, Article ID e6168, 2009.

[30] T. Yasuda, P. F. Bartlett, and D. J. Adams, "Kir and Kv channels regulate electrical properties and proliferation of adult neural precursor cells," Molecular and Cellular Neuroscience, vol. 37, no. 2, pp. 284-297, 2008.

[31] C. A. Ghiani, X. Yuan, A. M. Eisen et al., "Voltage-activated $\mathrm{K}^{+}$channels and membrane depolarization regulate accumulation of the cyclin-dependent kinase inhibitors p2 $7^{\mathrm{Kip} 1}$ and p21 ${ }^{\mathrm{CIP1}}$ in glial progenitor cells," Journal of Neuroscience, vol. 19, no. 13, pp. 5380-5392, 1999.

[32] J. Leng, L. Jiang, H. Chen, and X. Zhang, "Brain-derived neurotrophic factor and electrophysiological properties of voltage-gated ion channels during neuronal stem cell development," Brain Research, vol. 1272, no. C, pp. 14-24, 2009.

[33] D. H. Feldman, J. S. Thinschmidt, A. L. Peel, R. L. Papke, and P. J. Reier, "Differentiation of ionic currents in CNS progenitor cells: dependence upon substrate attachment and epidermal growth factor," Experimental Neurology, vol. 140, no. 2, pp. 206-217, 1996.

[34] S. C. Noctor, A. C. Flint, T. A. Weissman, R. S. Dammerman, and A. R. Kriegstein, "Neurons derived from radial glial cells establish radial units in neocortex," Nature, vol. 409, no. 6821, pp. 714-720, 2001.

[35] A. Attardo, F. Calegari, W. Haubensak, M. WilschBräuninger, and W. B. Huttner, "Live imaging at the onset of cortical neurogenesis reveals differential appearance of the neuronal phenotype in apical versus basal progenitor progeny," PLoS One, vol. 3, no. 6, Article ID e2388, 2008.

[36] Y. Ishii, S. Nakamura, and N. Osumi, "Demarcation of early mammalian cortical development by differential expression of fringe genes," Developmental Brain Research, vol. 119, no. 2, pp. 307-320, 2000.

[37] C. Englund, A. Fink, C. Lau et al., "Pax6, Tbr2, and Tbr1 are expressed sequentially by radial glia, intermediate progenitor cells, and postmitotic neurons in developing neocortex," Journal of Neuroscience, vol. 25, no. 1, pp. 247-251, 2005.

[38] S. C. Noctor, V. Martinez-Cerdeño, L. Ivic, and A. R. Kriegstein, "Cortical neurons arise in symmetric and asymmetric division zones and migrate through specific phases," Nature Neuroscience, vol. 7, no. 2, pp. 136-144, 2004.

[39] W. Haubensak, A. Attardo, W. Denk, and W. B. Huttner, "Neurons arise in the basal neuroepithelium of the early mammalian telencephalon: a major site of neurogenesis," Proceedings of the National Academy of Sciences of the United States of America, vol. 101, no. 9, pp. 3196-3201, 2004.
[40] T. Miyata, A. Kawaguchi, K. Saito, M. Kawano, T. Muto, and M. Ogawa, "Asymmetric production of surface-dividing and non-surface-dividing cortical progenitor cells," Development, vol. 131, no. 13, pp. 3133-3145, 2004.

[41] J. J. LoTurco, D. F. Owens, M. J. S. Heath, M. B. E. Davis, and A. R. Kriegstein, "GABA and glutamate depolarize cortical progenitor cells and inhibit DNA synthesis," Neuron, vol. 15, no. 6, pp. 1287-1298, 1995.

[42] J. Y. Joo, B. W. Kim, J. S. Lee et al., "Activation of NMDA receptors increases proliferation and differentiation of hippocampal neural progenitor cells," Journal of Cell Science, vol. 120, no. 8, pp. 1358-1370, 2007.

[43] D. R. Piper, T. Mujtaba, M. S. Rao, and M. T. Lucero, "Immunocytochemical and physiological characterization of a population of cultured human neural precursors," Journal of Neurophysiology, vol. 84, no. 1, pp. 534-548, 2000.

[44] M. D’Ascenzo, R. Piacentini, P. Casalbore et al., "Role of L-type $\mathrm{Ca}^{2+}$ channels in neural stem/progenitor cell differentiation," European Journal of Neuroscience, vol. 23, no. 4, pp. 935-944, 2006.

[45] G. H. Clayton, K. J. Staley, C. L. Wilcox, G. C. Owens, and R. L. Smith, "Developmental expression of ClC-2 in the rat nervous system," Developmental Brain Research, vol. 108, no. 1-2, pp. 307-318, 1998.

[46] S. Z. Young, M. M. Taylor, and A. Bordey, "Neurotransmitters couple brain activity to subventricular zone neurogenesis," European Journal of Neuroscience, vol. 33, no. 6, pp. 11231132, 2011.

[47] M. Demarque, A. Represa, H. E. Becq, I. Khalilov, Y. Ben-Ari, and L. Aniksztejn, "Paracrine intercellular communication by a $\mathrm{Ca}^{2+}$ - and SNARE-independent release of GABA and glutamate prior to synapse formation," Neuron, vol. 36, no. 6, pp. 1051-1061, 2002.

[48] D. D. Wang and A. R. Kriegstein, "Defining the role of GABA in cortical development," Journal of Physiology, vol. 587, no. 9, pp. 1873-1879, 2009.

[49] C. Wang, C. Shimizu-Okabe, K. Watanabe et al., "Developmental changes in KCC1, KCC2, and NKCC1 mRNA expressions in the rat brain," Developmental Brain Research, vol. 139, no. 1, pp. 59-66, 2002.

[50] H. Li, J. Tornberg, K. Kaila, M. S. Airaksinen, and C. Rivera, "Patterns of cation-chloride cotransporter expression during embryonic rodent CNS development," European Journal of Neuroscience, vol. 16, no. 12, pp. 2358-2370, 2002.

[51] W. Ma and J. L. Barker, "Complementary expressions of transcripts encoding GAD67 and GABA(A) receptor $\alpha 4, \beta 1$, and $\gamma 1$ subunits in the proliferative zone of the embryonic rat central nervous system," Journal of Neuroscience, vol. 15, no. 3, pp. 2547-2560, 1995.

[52] H. Le-Corronc, J. M. Rigo, P. Branchereau, and P. Legendre, "GABAA receptor and glycine receptor activation by paracrine/autocrine release of endogenous agonists: more than a simple communication pathway," Molecular Neurobiology, vol. 44, no. 1, pp. 28-52, 2011.

[53] L. Nguyen, J. M. Rigo, V. Rocher et al., "Neurotransmitters as early signals for central nervous system development," Cell and Tissue Research, vol. 305, no. 2, pp. 187-202, 2001.

[54] J. Antonopoulos, "Activation of the GABAA receptor inhibits the proliferative effects of bFGF in cortical progenitor cells," European Journal of Neuroscience, vol. 9, no. 2, pp. 291-298, 1997.

[55] L. Nguyen, B. Malgrange, I. Breuskin et al., "Autocrine/paracrine activation of the $\mathrm{GABA}_{A}$ receptor inhibits the proliferation of neurogenic polysialylated neural cell adhesion 
molecule-positive (PSA-NCAM ${ }^{+}$) precursor cells from postnatal striatum," Journal of Neuroscience, vol. 23, no. 8, pp. 3278-3294, 2003.

[56] T. F. Haydar, F. Wang, M. L. Schwartz, and P. Rakic, "Differential modulation of proliferation in the neocortical ventricular and subventricular zones," Journal of Neuroscience, vol. 20, no. 15 , pp. 5764-5774, 2000.

[57] T. Cesetti, T. Fila, K. Obernier et al., "GABAA receptor signaling induces osmotic swelling and cell cycle activation of neonatal prominin+ precursors," Stem Cells, vol. 29, no. 2, pp. 307-319, 2011.

[58] S. Nakanishi, "Molecular diversity of glutamate receptors and implications for brain function," Science, vol. 258, no. 5082, pp. 597-603, 1992.

[59] E. Muth-Köhne, S. Pachernegg, M. Karus, A. Faissner, and M. Hollmann, "Expression of NMDA receptors and $\mathrm{Ca}^{2+}$ impermeable AMPA receptors requires neuronal differentiation and allows discrimination between two different types of neural stem cells," Cellular Physiology and Biochemistry, vol. 26, no. 6, pp. 935-946, 2010.

[60] N. Nakamichi, T. Takarada, and Y. Yoneda, "Neurogenesis mediated by $\gamma$-aminobutyric acid and glutamate signaling," Journal of Pharmacological Sciences, vol. 110, no. 2, pp. 133149, 2009.

[61] D. W. Y. Sah, J. Ray, and F. H. Gage, "Regulation of voltageand ligand-gated currents in rat hippocampal progenitor cells in vitro," Journal of Neurobiology, vol. 32, no. 1, pp. 95110, 1997.

[62] T. Hirasawa, H. Wada, S. Kohsaka, and S. Uchino, "Inhibition of NMDA receptors induces delayed neuronal maturation and sustained proliferation of progenitor cells during neocortical development," Journal of Neuroscience Research, vol. 74, no. 5, pp. 676-687, 2003.

[63] K. Toriumi, A. Mouri, S. Narusawa et al., "Prenatal NMDA receptor antagonism impaired proliferation of neuronal progenitor, leading to fewer glutamatergic neurons in the prefrontal cortex," Neuropsychopharmacology, vol. 37, no. 6, pp. 1387-1396, 2012.

[64] K. C. Luk, T. E. Kennedy, and A. F. Sadikot, "Glutamate promotes proliferation of striatal neuronal progenitors by an NMDA receptor-mediated mechanism," Journal of Neuroscience, vol. 23, no. 6, pp. 2239-2250, 2003.

[65] M. Suzuki, A. D. Nelson, J. B. Eickstaedt, K. Wallace, L. S. Wright, and C. N. Svendsen, "Glutamate enhances proliferation and neurogenesis in human neural progenitor cell cultures derived from the fetal cortex," European Journal of Neuroscience, vol. 24, no. 3, pp. 645-653, 2006.

[66] V. Gallo, M. Pende, S. Scherer, M. Molne, and P. Wright, "Expression and regulation of kainate and AMPA receptors in uncommitted and committed neural progenitors," Neurochemical Research, vol. 20, no. 5, pp. 549-560, 1995.

[67] M. Forgac, "Vacuolar ATPases: rotary proton pumps in physiology and pathophysiology," Nature Reviews Molecular Cell Biology, vol. 8, no. 11, pp. 917-929, 2007.

[68] V. Marshansky and M. Futai, "The V-type $\mathrm{H}^{+}$-ATPase in vesicular trafficking: targeting, regulation and function," Current Opinion in Cell Biology, vol. 20, no. 4, pp. 415-426, 2008.

[69] L. Desfrere, M. Karlsson, H. Hiyoshi et al., "Na,K-ATPase signal transduction triggers CREB activation and dendritic growth," Proceedings of the National Academy of Sciences of the United States of America, vol. 106, no. 7, pp. 2212-2217, 2009.
[70] R. Creton, "The calcium pump of the endoplasmic reticulum plays a role in midline signaling during early zebrafish development," Developmental Brain Research, vol. 151, no. 12, pp. 33-41, 2004.

[71] D. S. Adams, A. Masi, and M. Levin, " $\mathrm{H}^{+}$pump-dependent changes in membrane voltage are an early mechanism necessary and sufficient to induce Xenopus tail regeneration," Development, vol. 134, no. 7, pp. 1323-1335, 2007.

[72] L. N. Vandenberg, R. D. Morrie, and D. S. Adams, "VATPase-dependent ectodermal voltage and $\mathrm{Ph}$ regionalization are required for craniofacial morphogenesis," Developmental Dynamics, vol. 240, no. 8, pp. 1889-1904, 2011.

[73] Y. Yan, N. Denef, and T. Schüpbach, "The vacuolar proton pump, V-ATPase, is required for notch signaling and endosomal trafficking in Drosophila," Developmental Cell, vol. 17, no. 3, pp. 387-402, 2009.

[74] T. Vaccari, S. Duchi, K. Cortese, C. Tacchetti, and D. Bilder, "The vacuolar ATPase is required for physiological as well as pathological activation of the Notch receptor," Development, vol. 137, no. 11, pp. 1825-1832, 2010.

[75] C. M. Cruciat, B. Ohkawara, S. P. Acebron et al., "Requirement of prorenin receptor and vacuolar $\mathrm{H}^{+}$-ATPasemediated acidification for Wnt signaling," Science, vol. 327, no. 5964, pp. 459-463, 2010.

[76] R. Kopan and M. X. G. Ilagan, "The canonical notch signaling pathway: unfolding the activation mechanism," Cell, vol. 137, no. 2, pp. 216-233, 2009.

[77] M. E. Fortini, "Notch signaling: the core pathway and its posttranslational regulation," Developmental Cell, vol. 16, no. 5, pp. 633-647, 2009.

[78] A. C. Tien, A. Rajan, and H. J. Bellen, "A notch updated," Journal of Cell Biology, vol. 184, no. 5, pp. 621-629, 2009.

[79] R. van Amerongen and R. Nusse, "Towards an integrated view of Wnt signaling in development," Development, vol. 136, no. 19, pp. 3205-3214, 2009.

[80] C. Lange, S. Prenninger, P. Knuckles, V. Taylor, M. Levin, and F. Calegari, "The $\mathrm{H}^{+}$vacuolar ATPase maintains neural stem cells in the developing mouse cortex," Stem Cells and Development, vol. 20, no. 5, pp. 843-850, 2011.

[81] S. H. Pasternak, R. D. Bagshaw, M. Guiral et al., "Presenilin-1, nicastrin, amyloid precursor protein, and $\gamma$-secretase activity are co-localized in the lysosomal membrane," Journal of Biological Chemistry, vol. 278, no. 29, pp. 26687-26694, 2003.

[82] L. Seugnet, P. Simpson, and M. Haenlin, "Requirement for dynamin during notch signaling in Drosophila neurogenesis," Developmental Biology, vol. 192, no. 2, pp. 585-598, 1997.

[83] N. Gupta-Rossi, E. Six, O. LeBail et al., "Monoubiquitination and endocytosis direct $\gamma$-secretase cleavage of activated Notch receptor," Journal of Cell Biology, vol. 166, no. 1, pp. 73-83, 2004.

[84] G. Struhl and A. Adachi, "Requirements for presenilindependent cleavage of notch and other transmembrane proteins," Molecular Cell, vol. 6, no. 3, pp. 625-636, 2000.

[85] D. D. Shaye and I. Greenwald, "Endocytosis-mediated downregulation of LIN-12/Notch upon Ras activation in Caenorhabditis elegans," Nature, vol. 420, no. 6916, pp. 686690, 2002.

[86] E. B. Sorensen and S. D. Conner, " $\gamma$-secretase-dependent cleavage initiates notch signaling from the plasma membrane," Traffic, vol. 11, no. 9, pp. 1234-1245, 2010.

[87] G. H. Clayton, G. C. Owens, J. S. Wolff, and R. L. Smith, "Ontogeny of cation-Cl- cotransporter expression in rat neocortex," Developmental Brain Research, vol. 109, no. 2, pp. 281-292, 1998. 
[88] D. F. Owens, L. H. Boyce, M. B. E. Davis, and A. R. Kriegstein, "Excitatory GABA responses in embryonic and neonatal cortical slices demonstrated by gramicidin perforated-patch recordings and calcium imaging," Journal of Neuroscience, vol. 16, no. 20, pp. 6414-6423, 1996.

[89] C. Rivera, J. Voipio, J. A. Payne et al., "The $\mathrm{K}^{+} / \mathrm{Cl}^{-}$cotransporter KCC2 renders GABA hyperpolarizing during neuronal maturation," Nature, vol. 397, no. 6716, pp. 251255, 1999.

[90] C. A. Hübner, V. Stein, I. Hermans-Borgmeyer, T. Meyer, K. Ballanyi, and T. J. Jentsch, "Disruption of KCC2 reveals an essential role of $\mathrm{K}-\mathrm{Cl}$ cotransport already in early synaptic inhibition," Neuron, vol. 30, no. 2, pp. 515-524, 2001.

[91] D. F. Owens and A. R. Kriegstein, "Is there more to GABA than synaptic inhibition?" Nature Reviews Neuroscience, vol. 3, no. 9, pp. 715-727, 2002.

[92] T. Cesetti, K. Obernier, C. P. Bengtson et al., "Analysis of stem cell lineage progression in the neonatal subventricular zone identifies EGFR+/NG2- cells as transit-amplifying precursors," Stem Cells, vol. 27, no. 6, pp. 1443-1454, 2009.

[93] S. C. Noctor, A. C. Flint, T. A. Weissman, W. S. Wong, B. K. Clinton, and A. R. Kriegstein, "Dividing precursor cells of the embryonic cortical ventricular zone have morphological and molecular characteristics of radial glia," Journal of Neuroscience, vol. 22, no. 8, pp. 3161-3173, 2002.

[94] L. Nguyen, B. Malgrange, S. Belachew et al., "Functional glycine receptors are expressed by postnatal nestin-positive neural stem/progenitor cells," European Journal of Neuroscience, vol. 15, no. 8, pp. 1299-1305, 2002.

[95] Y. Arai, J. N. Pulvers, C. Haffner et al., "Neural stem and progenitor cells shorten S-phase on commitment to neuron production," Nature Communications, vol. 2, no. 1, article 154, 2011.

[96] A. F. Pla, D. Maric, S. C. Brazer et al., "Canonical transient receptor potential 1 plays a role in basic fibroblast growth factor (bFGF)/FGF receptor-1-induced $\mathrm{Ca}^{2+}$ entry and embryonic rat neural stem cell proliferation," Journal of Neuroscience, vol. 25, no. 10, pp. 2687-2701, 2005.

[97] M. W. Bradbury, J. Crowder, S. Desai, J. M. Reynolds, M. Reynolds, and N. R. Saunders, "Electrolytes and water in the brain and cerebrospinal fluid of the foetal sheep and guineapig," Journal of Physiology, vol. 227, no. 2, pp. 591-610, 1972.

[98] S. J. Arnold, J. Sugnaseelan, M. Groszer, S. Srinivas, and E. J. Robertson, "Generation and analysis of a mouse line harboring GFP in the Eomes/Tbr2 locus," Genesis, vol. 47, no. 11, pp. 775-781, 2009.

[99] R. D. Hodge, T. D. Kowalczyk, S. A. Wolf et al., "Intermediate progenitors in adult hippocampal neurogenesis: Tbr2 expression and coordinate regulation of neuronal output," Journal of Neuroscience, vol. 28, no. 14, pp. 3707-3717, 2008.

[100] E. Taverna, C. Haffner, R. Pepperkok, and W. B. Huttner, "A new approach to manipulate the fate of single neural stem cells in tissue," Nature Neuroscience, vol. 15, no. 2, pp. 329$337,2012$.

[101] A. Sakaue-Sawano, H. Kurokawa, T. Morimura et al., "Visualizing spatiotemporal dynamics of multicellular cell-cycle progression," Cell, vol. 132, no. 3, pp. 487-498, 2008.

[102] Y. Kosodo and W. B. Huttner, "Basal process and cell divisions of neural progenitors in the developing brain," Development Growth and Differentiation, vol. 51, no. 3, pp. 251-261, 2009.
[103] Y. Tsunekawa, J. M. Britto, M. Takahashi, F. Polleux, S.-S. Tan, and N. Osumi, "Cyclin D2 in the basal process of neural progenitors is linked to non-equivalent cell fates," $E M B O$ Journal, vol. 31, no. 8, pp. 1879-1892, 2012.

[104] S. A. Fietz and W. B. Huttner, "Cortical progenitor expansion, self-renewal and neurogenesis-a polarized perspective," Current Opinion in Neurobiology, vol. 21, no. 1, pp. 23-35, 2011. 

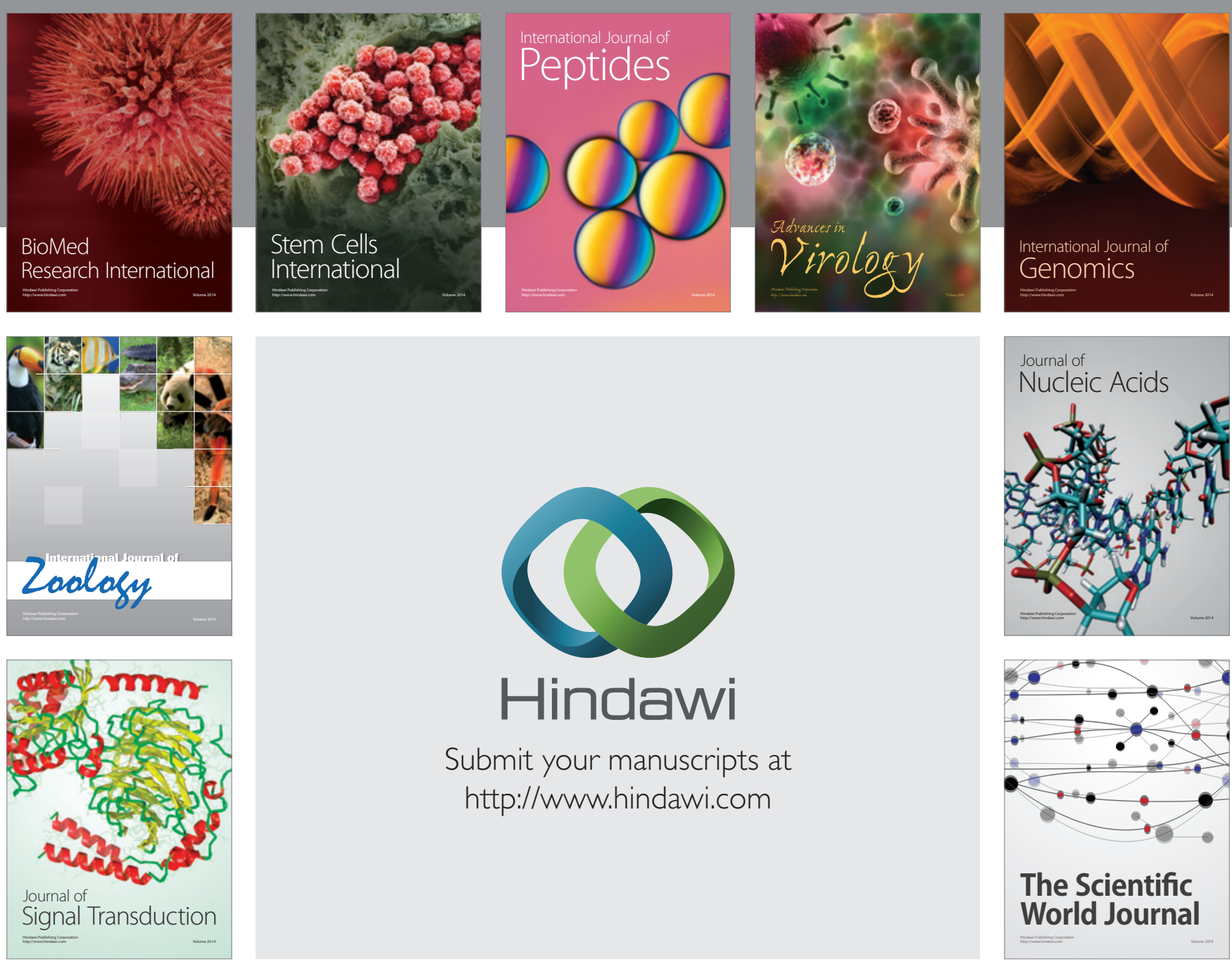

Submit your manuscripts at

http://www.hindawi.com
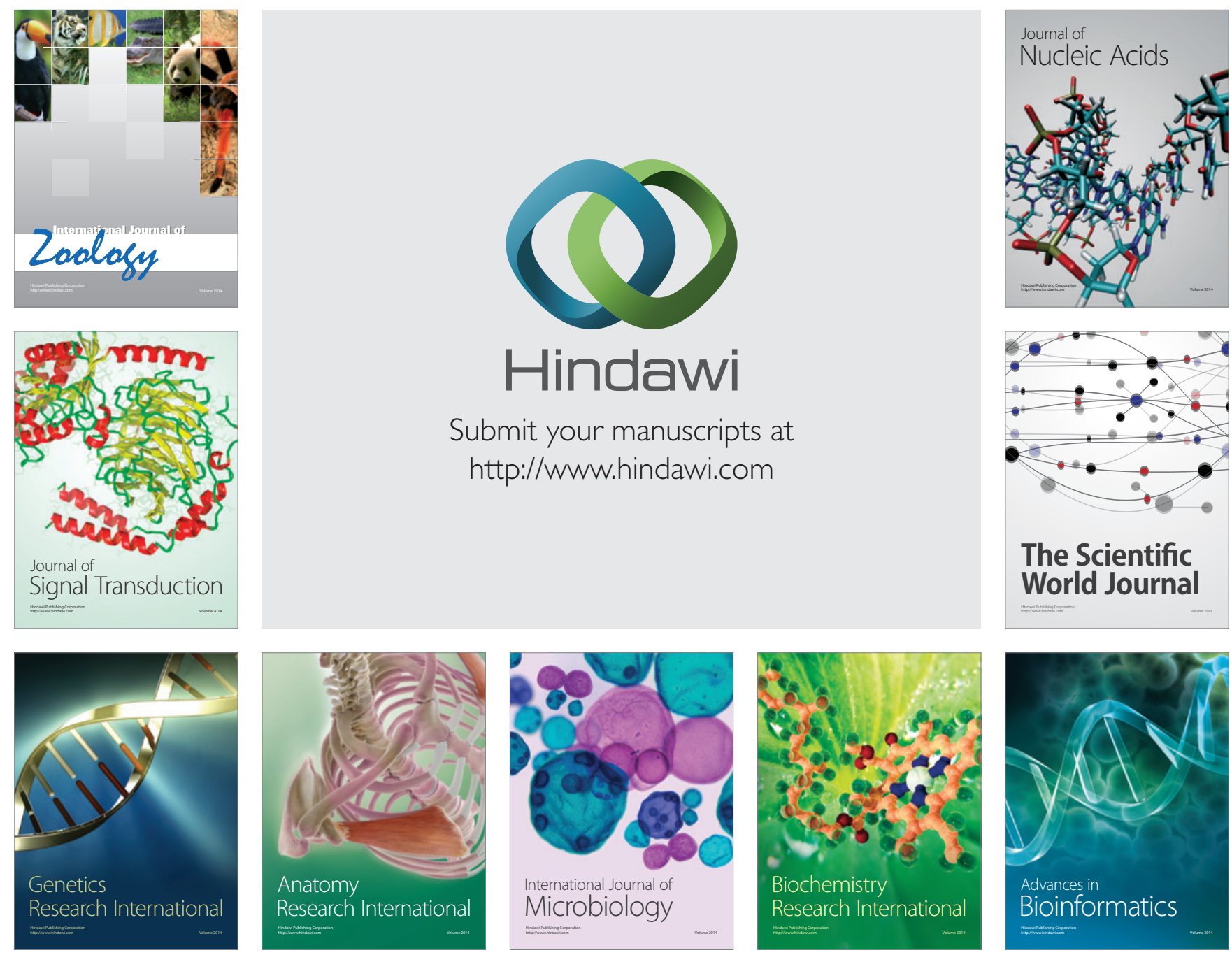

The Scientific World Journal
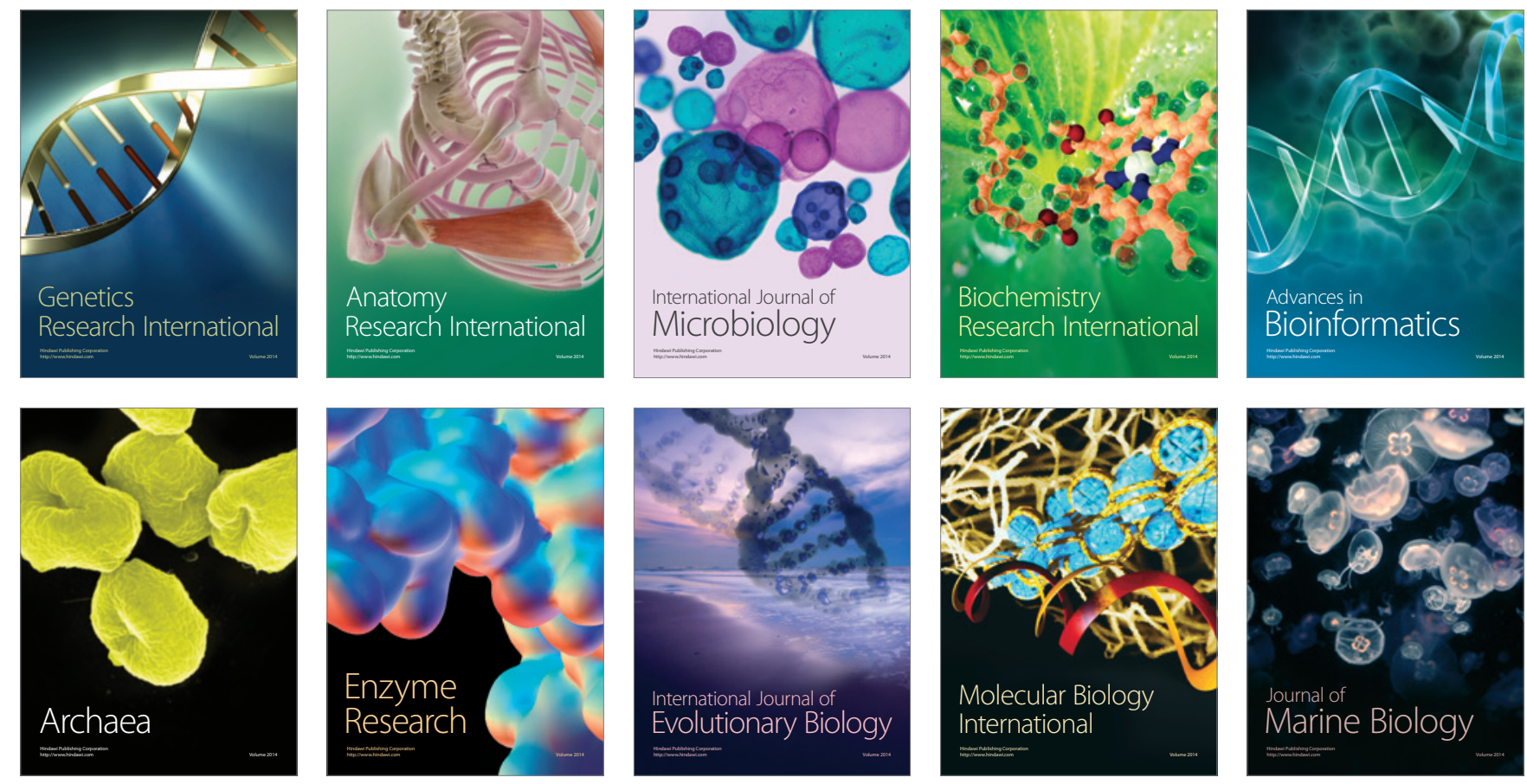